\title{
"Participar não é só fazer activismo": olhares de crianças e adolescentes moçambicanos
}

\section{"Participation is not just about activism": views of Mozambican children and adolescents \\ "Participar no es solo hacer activismo": opiniones de niños y adolescentes de Mozambique}

Elena Colonna*

\section{Resumo}

\begin{abstract}
A participação de crianças e adolescentes tem sido geralmente entendida como um envolvimento em processos de tomada de decisão e de acção em contextos públicos. A partir de uma pesquisa visual e participativa em três contextos de Moçambique, o presente artigo apresenta as oportunidades e as barreiras para a participação que crianças e adolescentes encontram nos seus contextos de vida quotidiana, a nível individual, nas relações de pares e na família. Os resultados indicam que, apesar dos desafios enfrentados, a expressão individual, as amizades e o contexto familiar representam espaços significativos para exercer a sua agência e participar no sentido de "tomar parte em" e sentir-se incluídos.
\end{abstract}

Palavras-chave: crianças, adolescentes, participação, Moçambique.

\section{Abstract}

Children and adolescents participation has generally been understood as involvement in decision-making processes and action in public contexts. Drawing on visual and participatory research in three Mozambican contexts, this paper presents the opportunities and barriers to participation that children and adolescents face in their everyday life, at individual level, in peer relationships and in their families. Results show that, despite the challenges faced, individual expression, friendships, and family represent significant spaces for exercising their agency and participating as "taking part in" and feeling included.

Keywords: children, adolescents, participation, Mozambique.

Recebido em 25/10/2019 - Aprovado em 09/04/2020

http://dx.doi.org/10.5335/rep.v27i2.11429

Professora italiana, doutora em Estudos da Criança e especialidade em Sociologia da Infância, pela Universidade do Minho. Docente da Universidade Eduardo Mondlane, Moçambique. Orcid: https://orcid.org/0000-0002-8639-9686. E-mail: elenamaputo@yahoo.it 


\section{Resumen}

La participación de niños, niñas y adolescentes en general se ha entendido como participación en procesos de toma de decisiones y de acción en contextos públicos. Basándose en una investigación visual y participativa en tres contextos mozambiqueños, este articulo presenta las oportunidades y las barreras para la participación que los niños y adolescentes enfrentan en sus contextos de vida cotidiana, individualmente, en las relaciones con sus pares y en sus familias. Los resultados indican que, a pesar de los desafíos enfrentados, la expresión individual, las amistades y el contexto familiar representan un espacio significativo para ejercer su agencia y participar como "tomar parte en" y sentirse incluido.

Palabras clave: niños, adolescentes, participación, Mozambique.

\section{Introdução}

Primeiro, participar não é só estar a fazer activismo, fazer programas da Radio, não é estar a participar no Parlamento Infantil, a participação começa dentro da nossa casa: se estão para tomar uma certa decisão e não nos consultam ou quando nós opinamos nos mandam calar, então esse é o primeiro obstáculo. Mardel, 17 anos, Maputo.

A teorização da participação no âmbito da Sociologia da Infância tem sido fortemente influenciada pela afirmação do direito à participação, no âmbito da Convenção dos Direitos da Criança. A partir da elaboração deste documento, tanto na prática quanto na investigação, foi-se difundindo, a nível global, um entendimento da participação que a identifica com o "falar e ser ouvido", isto é, com o envolvimento formal nos processos de tomada de decisão (MASON; BOLZAN, 2010). Neste contexto, uma das formas dominantes de pôr em prática a participação infantil é aquela em que as crianças são eleitas para representar os interesses de outras crianças dentro de estruturas institucionais formais. Entretanto, Wyness (2009) enfatiza que estas formas de participação tendem a reinforçar as desigualdades existentes entre grupos de crianças e têm menos probabilidade de incorporar as vozes dos grupos mais desfavorecidos e socialmente excluídos.

Mason e Bolzan (2010) defendem a necessidade de uma compreensão intercultural do conceito de participação e apresentam as diferentes interpretações do conceito que emergiram de um projecto de investigação em cinco países da região pacífico-asiática: a participação como um direito, a participação como "tomar parte em" e a participação como envolvimento na tomada de decisão. Nos países estudados, o entendimento da participação das crianças que resultou dominante foi o de "tomar parte em" actividades, tanto como indivíduos quanto sobretudo como participar com outros, como um grupo. De acordo com os autores, esta interpretação 
faz todo o sentido em culturas onde a ênfase é colocada na colectividade e as responsabilidades em relação à família e à comunidade prevalecem sobre os direitos individuais (MASON \& BOLZAN, 2010).

À luz de uma análise intercultural, Liebel e Saadi (2010) propõem uma visão mais ampla deste conceito, como uma inclusão activa e habitual nos processos sociais essenciais. Segundo estes autores, a participação não seria um tipo particular de comunicação com as crianças que deve ser organizado em modo pontual para finalidades específicas, mas uma efectivação seminal e quotidiana de uma agência significativa. Em trabalho anterior (COLONNA, 2012), já discuti a necessidade de olhar a participação de crianças e adolescentes em Moçambique mais como um envolvimento relevante nos difentes contextos de vida do que apenas como ter "voz" e participar nos processos de tomada de decisão. No presente artigo, a partir dos resultados de uma pesquisa visual e participativa, pretendo discutir o que significa a participação a nível individual, nas relações de pares e na família (LANSDOWN, 2018) para as crianças e os adolescentes (10-19 anos) de três contextos de Moçambique.

\section{Metodologia}

Fazer uma pesquisa participativa com crianças e adolescentes sobre a sua situação significa criar espaço para que eles possam contar a sua própria história, com as suas palavras e a partir dos seus pontos de vista (FRISINA, 2013). Neste empreendimento, é fundamental evitar perguntas de pesquisa que encorajam as respostas "desejadas" e constrangem as possibilidades dos participantes de expressar livremente as suas perspectivas (TISDALL; DAVIS; GALLAGHER, 2009).

Foi utilizado um método de pesquisa-acção participativa, inspirado no Photovoice, em que os adolescentes foram convidados a produzir fotos e desenhos para representar os seus pontos de vista e opiniões e responder as seguintes questões: O que te faz sentir bem? O que te faz sentir mal? Qual é o teu sonho? Os adolescentes explicaram individualmente as suas imagens aos investigadores e depois, em pequeno grupo, criaram categorias de imagens e debateram sobre elas, identificando barreiras e oportunidades. Finalmente, os participantes e os pesquisadores organizaram uma exposição das imagens para divulgar as "vozes" das crianças e adolescentes nas comunidades em que eles estão inseridos (HUSSEY, 2016; PALIBRODA, 2009; HUGHES, 2012). 
Num país como Moçambique, marcado por disparidades regionais, étnicas, culturais e socioeconômicas, existem muitas "infâncias" e "adolescências" e uma pluralidade de possibilidades, expectativas, experiências, significados e desafios para a implementação dos direitos de crianças e adolescentes. Foram assim seleccionados três diferentes contextos, isto é, três casos (STAKE, 2007) com características sociais, económicas, culturais, territoriais e infraestruturais específicas, onde as vidas de crianças e adolescentes moçambicanos podem ter lugar: uma grande cidade (Maputo), um município (Ribaué, em Nampula) e uma vila sede distrital (Pebane, em Zambézia).

Os participantes da pesquisa foram 31 meninas e 32 rapazes, com idade compreendida entre os 10 e os 19 anos de idade. A selecção dos participantes procurou garantir a diversificação do grupo, em termos de origens culturais, bairros ou experiências de vida para fornecer uma perspectiva mais ampla sobre as diferentes "infâncias" e "adolescências". Em particular, houve diversidade em termos de religião (muçulmana e diferentes igrejas cristãs), escolaridade (de $1^{\mathrm{a}}$ a $12^{\mathrm{a}}$ e fora do sistema escolar, incluindo quem nunca entrou na escola, quem abandonou e quem terminou o ensino secundário), deficiência, filhos, casamento, orfandade e situação familiar, trabalho e locar de residência, entre outros.

Em termos éticos, foi pedido o consentimento informado a todos os participantes e também aos encarregados de educação, para os menores de 18 anos. Todos autorizaram oralmente a usar os nomes reais. Entretanto, foi feita uma selecção da investigadora das imagens e falas sensíveis, pelas quais não são mencionados os nomes. A devolução dos resultados da pesquisa à comunidade através das "vozes" de crianças e adolescentes fez parte da metodologia proposta e do compromisso ético dos pesquisadores e considera-se que os benefícios em termos de empoderamento dos participantes foram maiores do que os riscos de exposição e represálias (GRAHAM, POWELL, TAYLOR, ANDERSON, \& FITZGERALD, 2013).

Para a elaboração deste artigo, foram seleccionados apenas os dados relacionados com a participação de crianças e adolescentes, a nível individual, com os pares e na família. Tratando-se de uma pesquisa visual e participativa, que procura mostrar a realidade com os olhos de crianças e adolescentes e fazer ouvir as suas vozes, o texto tem um caracter principalmente descritivo e as interpretações da investigadora sobre elas são limitadas. 


\section{"É uma maneira de ser autêntica": identidade e expressão dos adolescentes}

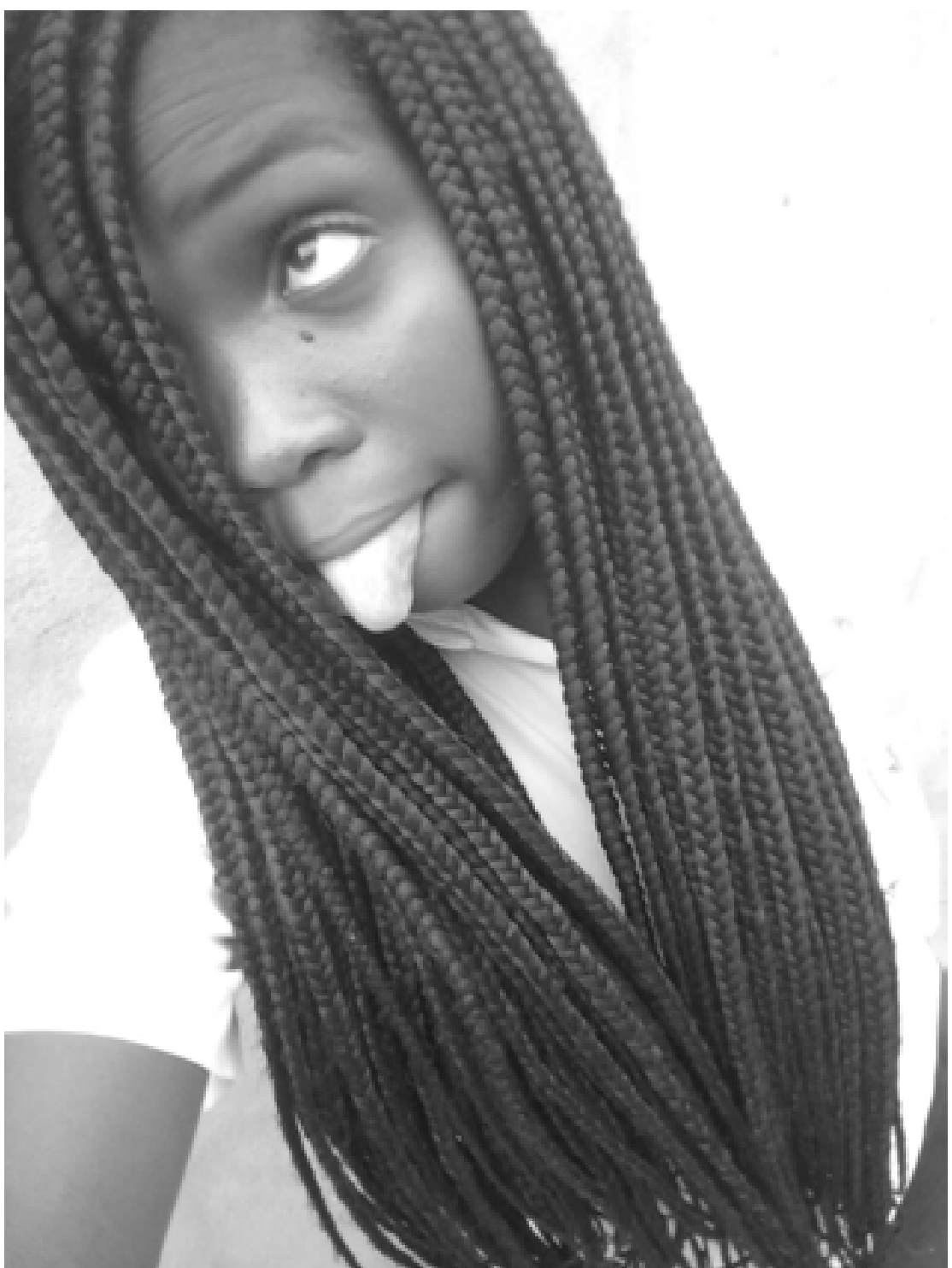

Gosto de ser diferente e especial. Eu estou a me a ver, eu na verdade gosto muito de tirar foto e gosto de ser autêntica, achei diferente olhar para o céu tentar ler o que está escrito apesar de não estar escrito nado no céu, foi uma maneira de me identificar. É uma maneira de eu mostrar a minha autenticidade, é um modo de ser autêntica, se formos autênticas as pessoas vão gostar do jeito que nos somos. Egineta, 15 anos, Maputo 
As crianças e os adolescentes participantes identificaram elementos individuais que são necessários para poder actuar de forma positiva na sociedade, isto é, para participar:

- requisitos biológicos: ter vida, saúde e necessidades básicas satisfeitas;

- requisitos identitários: ter identidade, emoções e sonhos e ter possibilidade de expressá-los;

- capacidades e competências: ter acesso a conhecimentos, ter habilidades para a vida e a capacidade de relacionar-se com os outros.

Para as crianças e os adolescentes dos diferentes contextos, a vida é o pressuposto básico para qualquer forma de participação e não é algo tido como garantido, mas que deve ser reconhecido e valorizado a cada momento: "Eu tenho vida e todos também devem ter vida" (Helton, 19 anos, Pebane). Muitos referem que "amam a vida" e, em particular, os de Ribaué enfatizam que se sentem bem quando comeram, tomaram banho e não têm nenhuma doença.

Ainda, para os adolescentes, é importante expressar através das palavras quem eles são realmente, a sua identidade, os seus sonhos e as suas emoções. Para os mais novos, apesar de eles acharem positivo partilhar e não guardar as suas emoções, costuma ser mais difícil conversar sobre o que sentem e preferem expressar-se através do canto, da dança e das brincadeiras. Os adolescentes mais velhos dos três contextos mencionam também a música, tanto escutar assim como produzir músicas, como algo que ajuda a gerir e expressar as suas emoções. Entretanto, a música é produzida de forma diferente de acordo com o texto onde os adolescentes se encontram inseridos: eles utilizam um aplicativo do telefone ou do computador no contexto urbano, em Maputo, enquanto usam instrumentos musicais como os batuques nas zonas mais rurais, em Pebane e Ribaué. Segundo André, 18 anos, de Maputo: “ $a$ música é a fonte de consolo em todos momentos. Se a tal pessoa quer expressar uma coisa, ela poderia recomendar uma música para expressar o que ela sente”.

Para os adolescentes de todos os contextos, os conhecimentos representam o primeiro passo em direcção a uma participação activa na sociedade: conhecer os seus direitos é importante para poder concretizá-los, estudar é o caminho para conseguir o emprego desejado e saber alguma coisa e ensiná-la aos outros aumenta também a autoconfiança: "eu já reparei uma coisa, os adolescentes gostam muito de mostrar que sabem uma coisa, fazer uma coisa nova, pode ser uma coisa da igreja, 
do basquete, da escola, só de eu saber que uma coisa que a outra não sabe, tipo me sinto mais, mais!" (Egineta, 15 anos, Maputo).

Os adolescentes de Maputo (15 - 19 anos) mencionam também algumas habilidades individuais que consideram importantes para alcançar a felicidade e realizar os seus sonhos: ser optimista e capaz de sorrir em qualquer ocasião; ter foco, determinação e força de vontade para alcançar os seus objectivos; ter paixão e dedicação nas actividades desempenhadas; ter capacidade de fazer as escolhas certas, avaliando custos e benefícios; não ter medo de tentar. Para elesm estas atitudes representam a chave do sucesso no presente e no futuro e podem ser cultivadas nas situações quotidianas, por exemplo, decidindo usar o dinheiro para ir passear na praia em vez de sentar na barraca a beber ou experimentando um novo passo de dança, mesmo sabendo que não vai sair bem.

Todos os adolescentes, independentemente da idade e do contexto, mostram o prazer de estarem juntos como outras pessoas e de poder ajudar quem precisa. Os adolescentes mais velhos de Maputo enfatizam a capacidade de colaborar com os outros para alcançar um objectivo. A capacidade de ouvir e respeitar a opinião dos outros, sobretudo dos mais velhos, é valorizada em todos os contextos. Outras práticas mencionadas, mas ainda pouco implementadas, são a demostração de afecto (sorrir, abraçar) e pedir ajuda em caso de necessidade: "devemos falar para os nossos mais velhos, para dizer que se acontecer uma coisa devemos correr para falar para eles resolver muito rápido" (Artur, 13 anos, Pebane). Finalmente, na relação com os outros, os adolescentes mencionam também a capacidade de não sucumbir a opinião dos outros, respeitando a si mesmos e aos seus gostos. Algumas meninas, que costumam ser gozadas pelos colegas devido à sua magreza, explicam:

[...] eu gosto do meu corpo assim. Pessoas falam que eu sou modelo, eu mesmo eu ser magrinha, não me importo. Meu corpo não é como vosso, quando nos dão corrida com cão e na educação física, vos ganho, vocês com vossa gordura também choram com vossa gordura e querem ser magras como eu (Meninas, 12 -13 anos, Pebane).

As barreiras que se colocam à livre expressão dos adolescentes são, em parte, especulares aos requisitos mencionados. Em termos biológicos, os adolescentes de Ribaué mencionam as doenças como algo que lhes impede de participar das actividades com os outros. As limitações nos requisitos identitários e nas capacidades e competências acabam se influenciando umas com as outras, sendo que os adolescentes de Maputo e Pebane mencionam a falta de autoestima e o medo como obstáculos para a sua participação: uma vez que "a maioria dos adultos pensa que as crianças não sabem nada, às vezes elas próprias se limitam”, acreditando que são 
novas e, portanto, sem valor e capacidades para participar. Esta ideia faz-lhes ter medo de aproximar a polícia ou outras autoridades competentes para apresentar queixa, caso aconteça alguma violação, tendo um impacto negativo na implementação de todos os seus direitos (provisão, protecção e participação). Finalmente, enquanto as condições económicas não tinham sido referidas pelos participantes como um elemento necessário para a participação, a falta de meios financeiros é apontada como um entrave, porque mina a sua autoeficácia (BANDURA, 1997), isto é, as crenças individuais sobre a sua capacidade de alcançar objectivos e sonhos. Este aspecto é mais notável nos contextos de Pebane e Ribaué, onde efectivamente os participantes viviam em condições materias desfavorecidas em relação aos da cidade de Maputo.

\section{"União de amigos" e "destruidoras de amizade": as relações de pares}

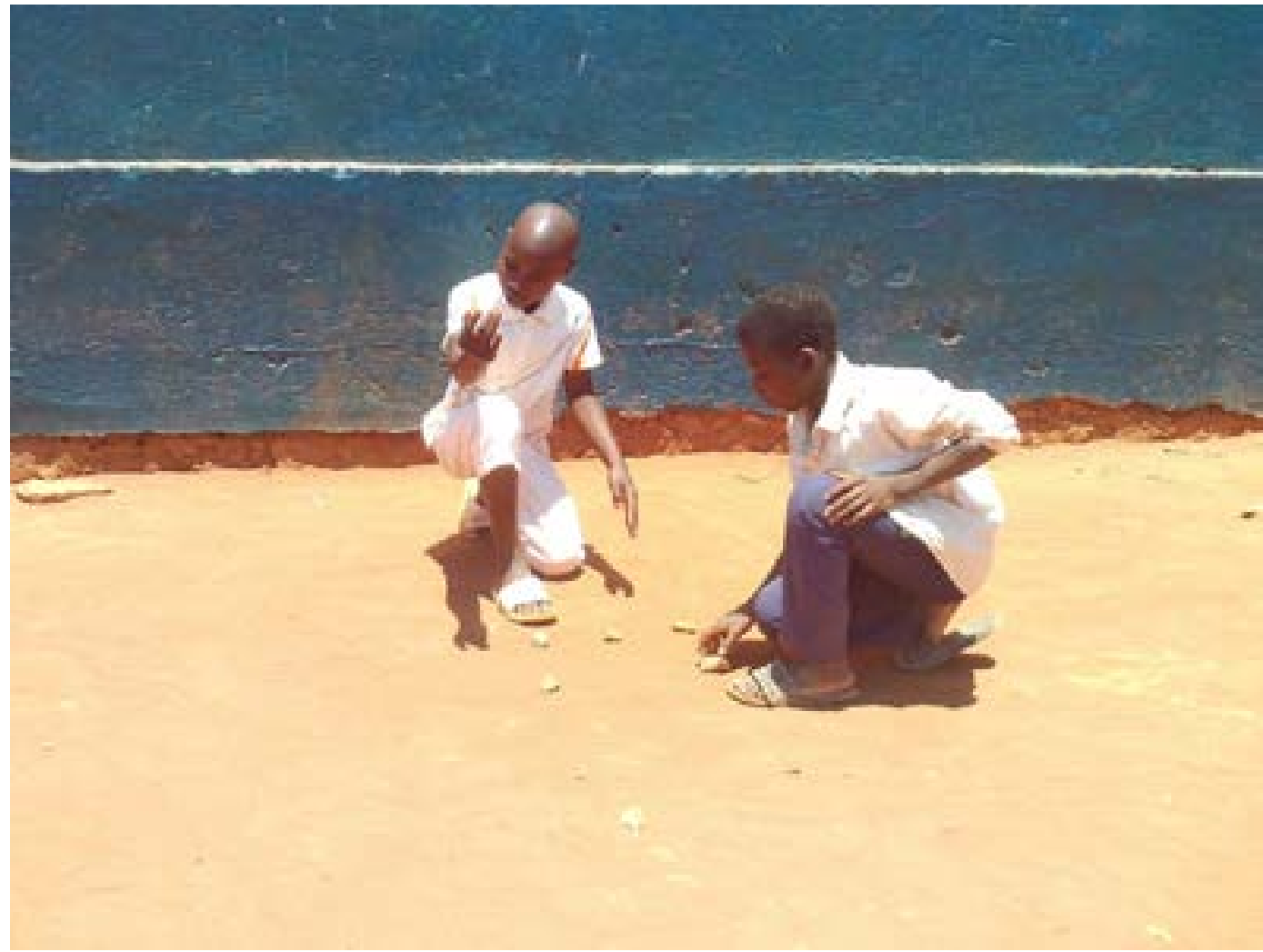

Eu gosto de brincar com os meus amigos. Brincar me faz sentir bem.

Delmiro, 13 anos, Ribaué 


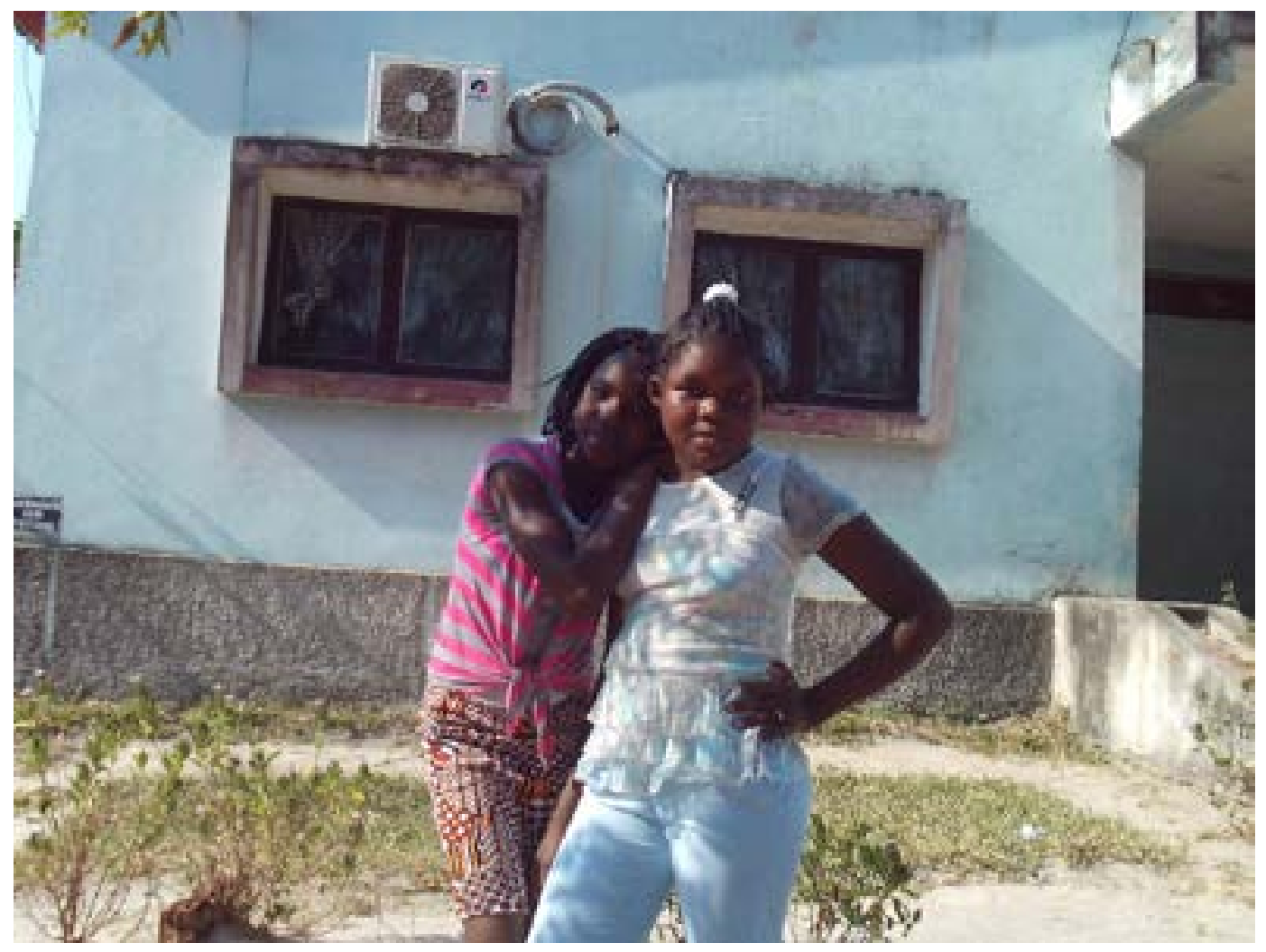

Essa foto saquei porque me faz sentir bem, porque gosto de conviver com as minhas amigas. Vanessa, 12 anos, Pebane

Os amigos representam um elemento central na vida de todos os participantes. Para as participantes de Pebane, de 12-14 anos, a amizade é "uma união de amigos, estamos unidos, ficamos unidos, falando sobre coisas boas”. Em geral, para os mais novos, a amizade é baseada sobretudo nas brincadeiras, enquanto os mais velhos enfatizam as conversas e os interesses comuns. As actividades entre amigos também se diferenciam de acordo com o género. Enquanto as meninas mais novas cantam, dançam e fazem jogos tradicionais e as mais velhas conversam, os rapazes de todas as idades são mais virados para actividades físicas e desporto (sobretudo futebol). Em muitos casos, sobretudo em Pebane e Ribaué, a amizade entre homens e mulheres é mais rara e não muito aceite socialmente. Para as crianças e os adolescentes, a amizade representa um espaço de aprendizagem, troca de ideias e partilha de conhecimentos. Enquanto os participantes mais novos, através dos 
amigos, "aprendem brincando", os mais velhos gostam de partilhar os seus conhecimentos para ficarem mais "famosos":

Esse jogo é txemurama, em português, "comermos arroz". Assim aí puseram um pau, estão aí a comer pouco pouco se deixar cair o pau, vai correr até bambu a pessoa vão lhe bater. Esse jogo nos ensina a sorrir. A brincar, a comer devagar, não comer depressa. Meninas, 12 - 14 anos, Pebane

Uma vez que ela vai ensinar uma pessoa e vai dizer eu é que lhe ensinei, acho que vai ser bonito e engraçado. Acho que a pessoa gosta, porque vai dizer: hi! eu é que lhe ensinei, eu é que ensinei Fátima eu é que ensinei, então os adolescentes gostam muito, ficam populares por causa disso, a maioria gosta de ser populares, ou aumenta teu próprios conhecimentos porque, quando você ensina outra pessoa acabas aprendendo coisas novas. Egineta, 15 anos, Maputo

Apesar de os amigos serem tão importantes, os participantes referem que não é fácil conseguir amigos verdadeiros, capazes de escutar, aconselhar e partilhar todos os momentos. Estes amigos se diferenciam dos conhecidos, com os quais podem andar juntos, "bater papo" e partilhar vícios (beber, fumar), mas não existe uma comunhão e uma expressão aberta da sua identidade e dos seus sentimentos. Ainda, os adolescentes de Maputo sugerem que é necessário ser proactivos na procura de amigos, não sendo recomendável ficar em casa e lamentar que os amigos não visitam, mas sim fazer o primeiro passo e ir ao encontro deles.

Entretanto, mesmo considerando a amizade uma experiência geralmente positiva, é juntos dos amigos que os participantes vivenciam diferentes situações de exclusão. Em particular, os adolescentes sentem-se mal quando: os pares excluem-nos das conversas e das brincadeiras; os pares "roubam-lhes" os amigos; os pares gozam com eles; os pares querem mostrar-se superiores. As participantes de Pebane, de 12 - 14 anos de idade assim descrevem o conceito de "destruidoras de amizade":

Quando encontra as outras a brincar, quando essa aproxima, outras proíbem essa de brincar. Porque ela foi a última a chegar. Ou quando querem dançar, alguém prepara o passo dele para dançar, então vem uma menina Ihe proíbem, falam para procurar alguém para dançar com ele. No dia seguinte, ela basta ver algo, ou comprar bolacha, ela proíbe, fala 'vocês me proibiram de brincar com vocês, também não vou-te dar minha bolacha'. Aqui em Pebane, amizade também não dura porque tem destruidoras de amizade. Estão na escola essas pessoas. Vem vê Fatu e Bia a brincar ali, ela chega, vai leva ela e vai com ela onde ela vai. Fala no ouvido e nós que ficamos ali, ficamos tristes.

Em muitos casos, a pressão de pares e a ridicularização no grupo acabam impedindo aos adolescentes de fazerem o que eles gostam, por vergonha. Finalmente, outra barreira vivenciada na amizade, é a dificuldade de crianças e adolescentes de abrir-se, contar as suas preocupações e pedir ajuda aos amigos: 
Há muitos rapazes ou meninas que gostam de se angustiar, serem por exemplo essa menina aqui está nervosa, está triste, não quer contar para amiga dela o que está a sentir, ela foi violada ou aconteceu alguma uma coisa e ela não quer contar para amiga dela, então por isso fica sobre ela só, se aconteceu uma coisa, ela se contar para amiga podia-lhe ajudar a dizer essa coisa que ela está a sentir. Rapazes, 12 -13 anos, Pebane

\section{"Uma mãe ou pai dizer 'amo-te' a informar a um filho é muito difícil": a vida familiar}

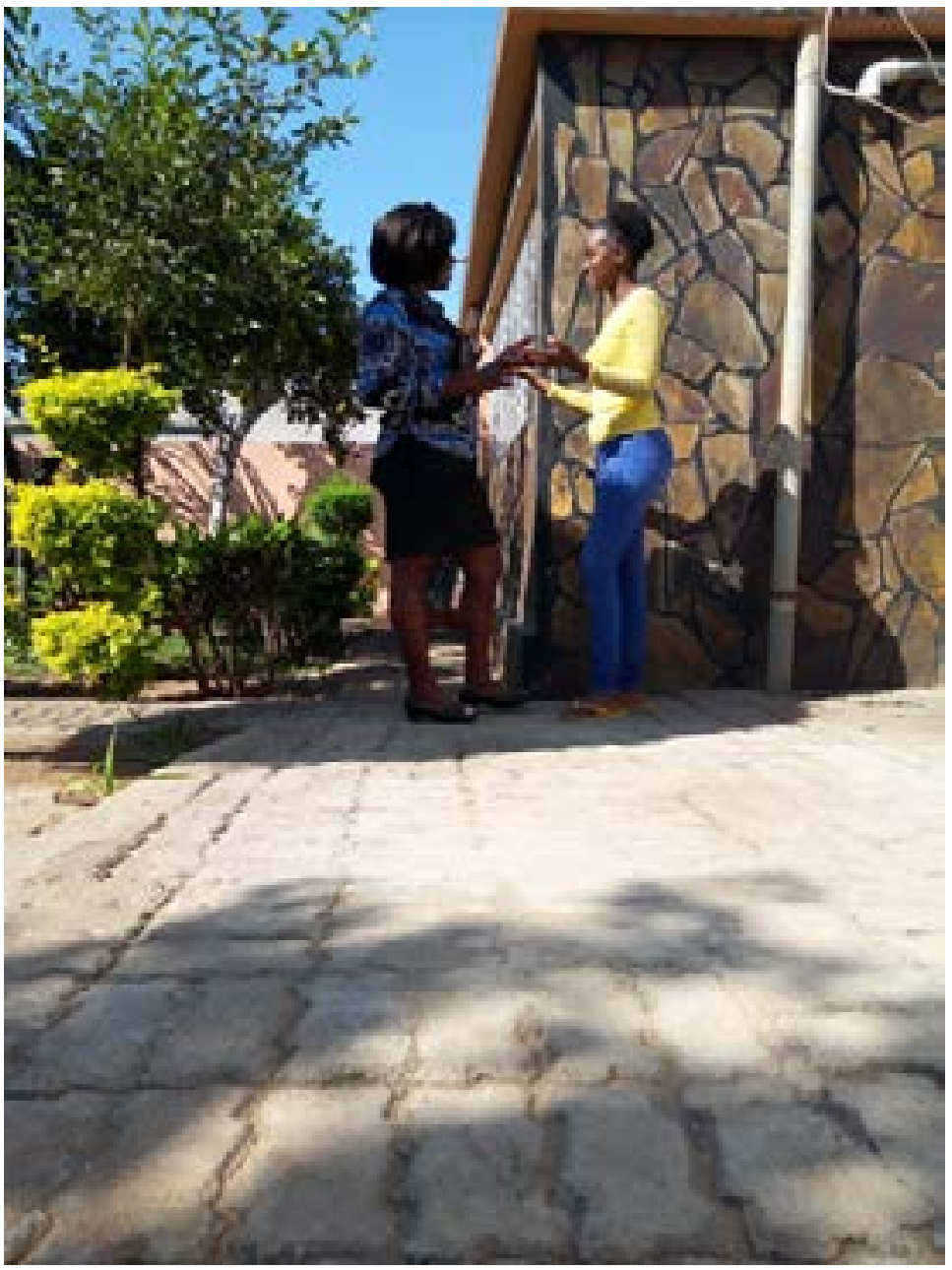

Outra coisa que torna o meu dia especial e alegre, é conversar com a minha mamã. Érica, 16 anos, Maputo 
A família constitui um espaço muito importante de convivência e inclusão social, entretanto apresenta oportunidades e barreiras para a participação de crianças e adolescentes, em diferentes âmbitos:

- existência da família;

- respeito pelos direitos das crianças;

- relação pais - filhos;

- apoio recíproco;

- liberdade.

Os adolescentes consideram que "a família é a base de tudo. Tudo o que você pode ser, o que você pode conquistar também está na base da família e muitas vezes não beneficia só você, beneficia também a família, então a família é uma coisa muito importante" (Rapazes, 12 -13 anos, Pebane). Estar com a família e ver os familiares felizes é motivo de satisfação para os participantes da pesquisa. Em geral, os adolescentes valorizam os pais, os irmãos, os tios e os avós, dependendo da sua situação familiar e o nascimento de mais um membro da família é recebido com grande alegria: "quando a tua mãe está grávida, já deu filho, você fica emocionado, ter um irmão ou uma irmã” (Artur, 13 anos, Pebane).

Quando as meninas se tornam mães, uma realidade bastante comum em Moçambique onde cerca metade das mulheres têm um filho antes dos 18 anos (UNICEF, 2015), os outros familiares passam para o segundo plano e o bem-estar dos seus próprios filhos é considerado como principal influenciador do seu próprio bem-estar:

A minha filha, eu gosto assim porque ela está bem, amanheceu bem. Ela é minha filha, e ela está bem, e ela está a brincar. Eu não fico bem quando está doente. Assim se está aí deitada melhor levar ao hospital, eu também vou ficar bem e ela também vai ficar bem. Mércia, 16 anos, Ribaué

Nos contextos estudados, não ter família é, portanto, motivo de tristeza. Esta situação é apresentada por um participante de Maputo, que nunca conheceu o pai e sente falta de um guia masculino na sua vida, e também por um participante de Ribaué que está preocupado com a ausência dos avós, uma vez que a tradição local exige que sejam eles a assinar na cerimónia de casamento. A distância dos familiares representa outro motivo de tristeza, amenizada pelas visitas ocasionais que acontecem: "eu não gosto de ficar longe dos meus irmãos. Nos somos 9, depois 
eles saíram, outro para África do Sul, outros foram viver nas outras casas, eu vou la nas férias, às vezes eles vêm”(Isaura, 12 anos, Maputo).

$\mathrm{O}$ conhecimento e o respeito pelos direitos das crianças representariam uma oportunidade de participação na vida familiar na perspetiva de crianças e adolescentes envolvidos no estudo: "os direitos, os nossos pais devem conhecer os nossos direitos porque ser um pai assim uma criança fica lá muito feliz, o dia depois os nossos pais nos dão amor, carinho, isso" (Rapazes, 12 -13 anos, Pebane). Entretanto, em muitos casos, estes direitos não são conhecidos e implementados e a vida dos participantes é marcada por experiências de diferentes tipos de violência doméstica. A situação é particularmente crítica para os enteados, que costumam ser discriminados e maltratados por madrastas e padrastos, como referido pelos adolescentes de Pebane e Ribaué.

Alguns adolescentes, sobretudo os mais velhos de Maputo, referem ter uma relação próxima e aberta com os seus pais e esta é uma experiência positiva para eles. Para os outros, existem geralmente espaços limitados de conversa. Mesmo sobre os comportamentos dos filhos, os adultos costumam conversar só entre eles, enquanto os filhos gostariam de ser corrigidos abertamente pelos pais. No caso os pais não tomem a iniciativa de falar com eles, alguns adolescentes sugerem que eles mesmos deveriam aproximar-se dos pais para conversar, mas outros confessam que têm medo de dar o primeiro passo, porque acham que os pais poderiam zangar e levantar a voz, não considerando apropriado este tipo de interacção:

Num quintal, uma criança pode falar 'pai, aqui podemos jantar assim', o pai vai recusar, vai dizer 'você não tem idade de falar, eu é que sou mais velho que mando aqui', determinar a criança, 'você não nasceu a mim!' Rapazes, 15 - 21 anos, Ribaué

Segundo os participantes, existem pais que não têm paciência de ensinar aos filhos e ficam nervosos com facilidade quando estes erram. A expressão de afecto através de gestos e palavras é outra barreira identificada na relação entre pais e filhos. Na melhor das hipóteses, sobretudo em Pebane e Ribaué, o amor dos pais é manifestado através do apoio material às necessidades dos filhos. Da mesma forma, os filhos não estão acostumados a manifestar verbalmente o seu afecto para os pais e a agradecer por aquilo que têm feito por eles. Finalmente, a sinceridade entre pais e filhos é valorizada pelos participantes: eles não devem mentir para os adultos para que estes possam continuar a confiar neles. Ao mesmo tempo, quando um dos pais não é sincero com a família, ausentando-se de casa sem informar é motivo de tristeza e preocupação para os filhos. 
As crianças e adolescentes consideram muito importante o apoio dos pais, em termos emocionais mas sobretudo materiais, para satisfazer as suas necessidades e alcançar os seus objectivos. A falta de apoio por parte dos pais promove mal-estar nas crianças e nos adolescentes. Da mesma forma, os participantes reconhecem que é seu dever apoiar os pais e contribuir para a vida familiar, cuidando dos irmãos, realizando trabalho domésticos e colaborando nas actividades agrícolas e nos negócios da família. Um dele refere que sente-se mal quando um familiar distante precisa de ajuda, por exemplo porque está doente, e ele não consegue apoiar. Um jovem de Ribaué refere ter medo da morte porque deixaria os familiares sem o seu apoio. Segundo os participantes, a inveja representa uma barreira para o apoio no seio da família, levando alguns familiares a envolver-se na feitiçaria para prejudicar os outros:

[...] tem inveja que a própria família vira uma coisa perigosa. Por exemplo quando você tem, o outro não tem, então têm pessoas da família que se envolvem nas drogas tradicionais para te prejudicar, porque você tem e eles não ficaram felizes (Helton, 19 anos, Pebane).

A liberdade experienciada no seio das famílias é um aspecto discutido pelos participantes. Em particular, eles criticam o facto de os pais lhes proibirem de sair para brincar (no caso dos mais novos) ou para ir as festas (no caso dos mais velhos). O que eles acham apropriado é estabelecer limites, uma vez que a proibição total prejudica a participação e o bem-estar de crianças e adolescentes e também os motiva a infringir a regra estabelecida. Os adolescentes de Maputo referem que, em relação à escolha do curso universitário, hoje os pais deixam maior liberdade em relação ao passado. Pelo contrário, as adolescentes de Ribaué que terminaram a $12^{\text {a }}$ estão à espera de os pais conseguirem uma oportunidade para elas continuarem os estudos. 


\section{Considerações finais}
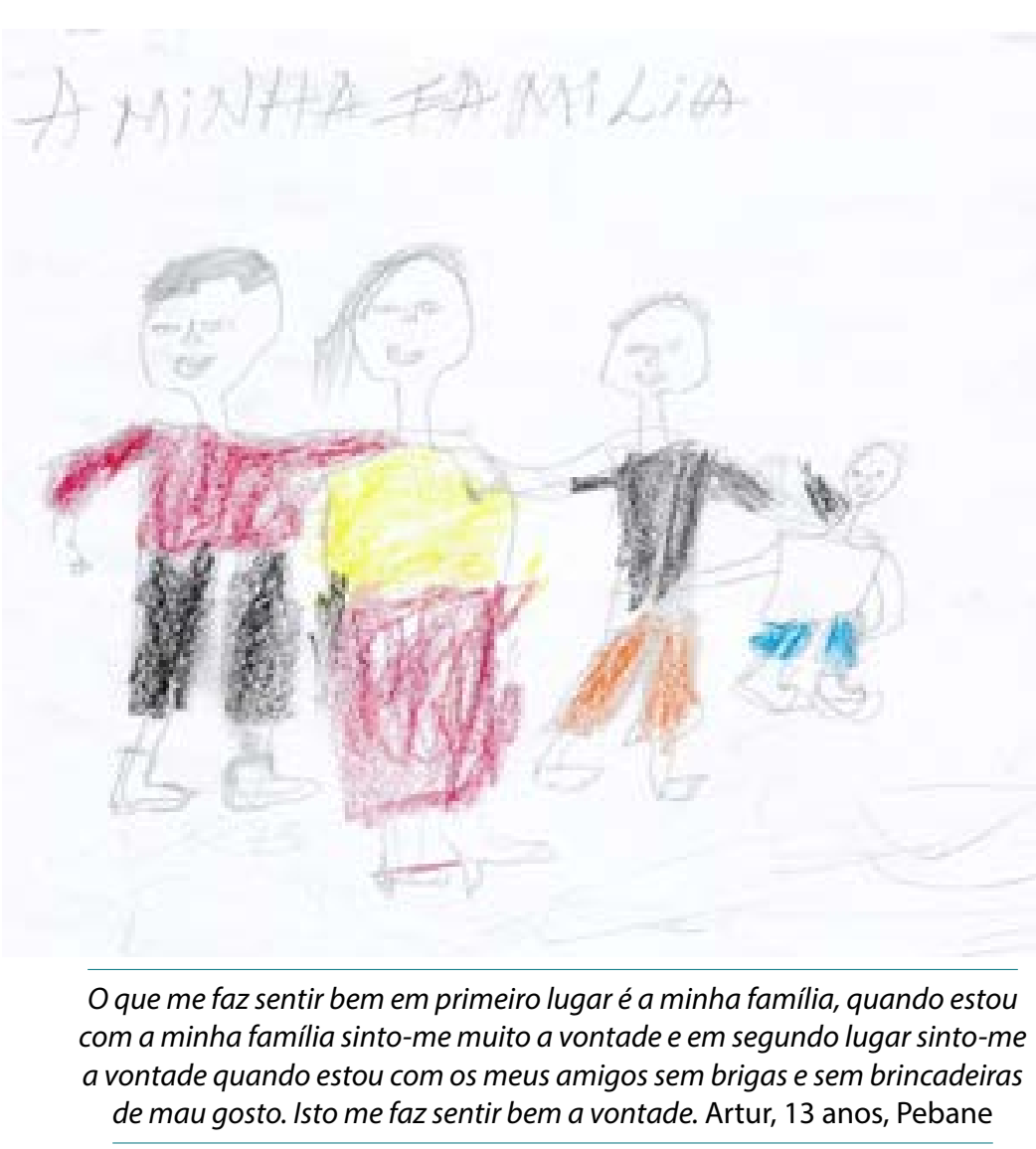

Para as crianças e os adolescentes envolvidos no estudo, participar não é apenas o envolvimento em actividades e contextos formalmente reconhecidos como tendo um impacto na vida social, mas sim um exercício quotidiano, que começa de si mesmos, da forma individual de expressar-se e apresentar-se ao mundo e, passando pelas relações interpessoais com os amigos e os familiares, chega até a escola, a comunidade e a sociedade em geral.

A inclusão social, na sua dimensão relacional, isto é, experimentar um sentimento de pertença e aceitação (BAILEY, 2005) é mencionada por todos os participantes como uma experiência positiva, seja com amigos, familiares e vizinhos, assim como na igreja ou mesquita, nas equipas e nas associações locais. No contexto da Convenção dos Direitos das Crianças, três principais direitos remetem para a participação de crianças e adolescentes na sociedade: 
- a liberdade de expressão, associação e religião;

- o direito à informação;

- o direito a dar opinião e esta ser considerada, em todos os assuntos que os afectam.

Ao longo da pesquisa, nota-se que o primeiro direito, com algumas barreiras, é vivenciado pelos adolescentes de todas as idades e de todos os contextos, sobretudo ao nível dos amigos, da família e da comunidade. Os adolescentes participam de diferentes formas na sociedade, através da brincadeira, da música, da dança, do desporto e da religião, através da sua contribuição nas actividades domésticas e produtivas na família e na comunidade. Entretanto, o acesso à informação e o direito à opinião representam uma realidade ainda "incipiente" e reservada quase exclusivamente aos adolescentes mais velhos e que vivem no contexto urbano de Maputo.

As crianças e os adolescentes moçambicanos têm poder de decisão limitado desde o nível familiar, em particular as meninas que são casadas com homens mais velhos, até ao nível comunitário e ao nível nacional de discussão de políticas (BIZA, 2007). Entretanto, a pesquisa mostrou que eles encontram espaço para promover novos conhecimentos, atitudes e práticas nas suas vidas, nas suas relações de amizade e nas suas famílias. Enfrentar desafios e relações de poder desiguais não significa ficar calados ou ser passivos e as situações difíceis podem inspirar os mais novos a engendrar soluções criativas (HONWANA, 2014).

\section{Nota}

1 Os dados apresentados são resultado de uma pesquisa desenvolvida com financiamento do UNICEF Moçambique no âmbito da Análise da Situação dos Adolescentes em Moçambique 2018. Entretanto, as opiniões expressas no artigo são da exclusiva responsabilidade da autora, não reflectindo a política ou a posição da UNICEF.

\section{Referências}

BAILEY, R. Evaluating the relationship between physical education, sport and social inclusion. Educational Review, v. 57, n. 1, p. 71-90, 2005. doi:10.1080/0013191042000274196

BANDURA, A. Self-Efficacy: The exercise of control. New York: Freeman, 1997.

BIZA, A. M. Associações de Jovens, Estado e Política em Moçambique. Maputo: IESE, 2007. 
COLONNA, Elena. Eu é que fico com a minha irmã. Vida quotidiana das crianças na periferia de Maputo. Braga: Universidade do Minho, 2012.

FRISINA, A. Ricerca visuale e trasformazioni socio-culturali. Novara: UTET, 2013.

GRAHAM, A., Powell, M., Taylor, N., Anderson, D., \& Fitzgerald, R. Ethical research involving children. Florence: UNICEF Office of Research-Innocenti, 2013.

HONWANA, A. Juventude, Waithood e Protestos Sociais em África. Desafios para Moçambique Maputo: IESE, 2014, p. 399-412.

HUGHES, J. SAGE Visual Methods. London: SAGE, 2012.

HUSSEY, J. Photovoice Facilitator's Guide. Wormerveer: Rutgers, 2016.

LANSDOWN, G. Conceptual Framework for Measuring Outcomes of Adolescent Participation. New York: UNICEF, 2018.

LIEBEL, M.; SAADI, I. Commentary 3: Participation in the traps of cultural diversity. In B. a. Percy-Smith, A handbook on children and young people's participation: Perspectives from theory and practiceLondres: Routledge, 2010, p. 150 - 153.

MASON, J.; BOLZAN, N. Questioning Understandings of Children's Participation. Applying a Cross-cultural Lens. In B. T. Percy-Smith, A handbook of children and young people's participation: Perspectives from theory and practice. Londres: Routledge, 2010.

PALIBRODA, B. A practical guide to Photovoice. Manitoba: The Prairie Women's Health Centre of Excellence, 2009.STAKE, R. E. A arte da investigação com estudos de caso. Lisboa: Fundação Calouste Gulbenkian, 2007.

TISDALL, E. K.; DAVIS, J. M.; GALLAGHER, M. Researching with Children \& Young People. London: Sage, 2009.

UNICEF. Casamento Prematuro e Gravidez na Adolescência em Moçambique: Causas e Impactos. Maputo: UNICEF Moçambique, 2015.

WYNESS, M. Children Representing Children: Participation and the problem of diversity in UK youth councils.Childhood,v. 16,n.4,535-552,2009.doi:https://doi.org/10.1177/0907568209344274 